\title{
The Synthesis of Five Heptapeptide Analogues by the Solid-phase Technique. Side Reactions of Tyrosyl and Glutamyl Residues
}

\author{
PER SøRUP, ${ }^{a}$ HANNE BRAAE, ${ }^{a}$ PREBEN VILLEMOES ${ }^{b}$ and THORKILD CHRISTENSEN ${ }^{b}$
}

a Chemistry Laboratory III, H. C. Ørsted Institute, University of Copenhagen, 5 Universitetsparken, DK-2100 Copenhagen Ø, Denmark, and Institute for Experimental Immunology, University of Copenhagen, 71 Nørre Allé, DK-2100 Copenhagen Ø, Denmark and ${ }^{b}$ The Danish Institute of Protein Chemistry, 4 Venlighedsvej, DK-2970 Hørsholm, Denmark

Five heptapeptides with the general formula H-Tyr-X-X-X-Ala-Ala-Gly-OH $\quad(X=T y r$ or Glu) * were prepared by the solid-phase technique using an automated synthesizer. Coupling and $\alpha$-amino deblocking yields were monitored by potentiometric perchloric acid titration, and cleavage of the peptides from the solid support was achieved by hydrogen bromide/trifluoroacetic acid-anisole $(9: 1, \mathrm{v} / \mathrm{v})$.

The formation of $N$-terminal pyroglutamyl during coupling could be followed by titration, and the corresponding truncated peptides isolated by ion exchange chromatography. Peptides containing a 3-benzyltyrosine residue, due to the $\mathrm{O} \rightarrow \mathrm{C}$ rearrangement of $O$-benzyltyrosyl during cleavage, were separated from the main product in yields of $21-36 \mathrm{~mol} \%$.

Uncommon, slow modes of titration of certain peptide sequences, e.g. H-Tyr(Bzl)Glu(OBzl)-Glu(OBzl)-Tyr(Bzl)-Ala-Ala-Gly-Oresin, were observed and tentatively assigned to conformational properties of the protected and resin-bound peptide chains.

The importance of the solid-phase technique ${ }^{1}$ for the synthesis of oligopeptides is steadily increasing.2 A straightforward application of the technique is, however, often hampered by side reactions, e.g. chain terminations, during the build-up of the peptide, which may lead to complex mixtures and low yields. ${ }^{3}$

Monitoring of the synthesis, i.e. determination

* Abbreviations. The multichain co-polypeptide poly(Lys) poly(Tyr,Glu)-poly(DL-Ala) is denoted (T,G)-A-L; $t$-butyloxycarbonyl-, Boc-; benzyl-, Bzl- and the pyrrolid-2-one-5-carboxylic (pyroglutamic) acid residue, <Glu.

0302-4369/79/090653-11\$02.50

(C) 1979 Acta Chemica Scandinavica of the efficiency of the consecutive deblocking and coupling reactions is, thus, a prerequisite for a successful outcome of a solid-phase preparation. Several monitoring systems have been developed, and some are applicable to the automated peptide synthesizers now commercially available..$^{4,5}$ Knowledge of the prospects of the synthesis and - at least in principle-high yields are, thus, obtainable.

Side reactions during cleavage of the peptide from the solid support may, however, be an additional cause of low over-all yields., In a previous paper ${ }^{6}$ the use of DEAE-Sephadex ion exchange chromatography for the fractionation and characterization of crude peptide preparations was described. Here, this technique is applied to peptides synthesized with monitoring of deblocking and coupling reactions by means of potentiometric perchloric acid titrations." The purpose was to evaluate the extent to which side reactions during coupling and cleavage, respectively, may influence the homogeneity of simple peptides synthesized by the solid-phase technique.

The observations were made in the preparation of five heptapeptide analogues, containing tyrosine and glutamic acid residues (Table 1), which have been used in a study of the antigenicity of a branched polypeptide, (T,G)-A L. $^{8-11}$ Side reactions affecting tyrosine and glutamic acid residues have been described both in the build-up ${ }^{12,13}$ and the cleavage phases. ${ }^{13-19}$ In this study, however, these side reactions could be readily monitored, and the requested peptides isolated in reasonable yields. 
Table. 1. The DEAE-Sephadex fractionated synthetic heptapeptides.

Peptide

H-Tyr-Glu-Glu-Tyr-Ala-Ala-Gly-OH

H-Tyr-Tyr-Glu-Glu-Ala-Ala-Gly-OH

H-Tyr-Glu-Tyr-Glu-Ala-Alá-Gly-OH

H-Tyr-Glu-Tyr-Tyr-Ala-Ala-Gly-OH

H-Tyr-Glu-Glu-Glu-Ala-Ala-Gly-OH
Amino acid analysis ${ }^{a}$

\author{
$1.00: 2.03: 2.00: 1.98^{b}$ \\ $1.00: 2.05: 2.05: 1.98$ \\ $1.00: 2.00: 1.99: 1.91$ \\ $1.00: 1.98: 1.01: 2.94$ \\ $1.00: 2.06: 3.05: 0.97$
}

${ }^{a}$ Gly:Ala:Glu:Tyr. ${ }^{b}$ Data from peak (b) of Fig. 3.

Rates of the potentiometric titrations were extraordinary slow for some of the sequences studied, and an associated premature automatic shut-off initially blurred coupling yields in some of the reported syntheses. The slow mode of titration seems, however, not in general to affect the applicability of the monitoring system, since such slow modes may be depicted by the potential versus time curves recorded during titration. Their cause, which has tentatively been assigned to conformational properties of the protected peptide chains, and their possible consequences remain, however, to be elucidated.

\section{EXPERIMENTAL}

Solvents and reagents. Dichloromethane (pro analysi) was obtained from Merck, Darmstadt; glacial acetic acid (pronalys) from May \& Baker, Dagenham; $\quad N, N^{\prime}$-dicyclohexylcarbodiimide (purum) and triethylamine (puriss) were obtained from Fluka, Buchs. Boc-amino acids, Boc-Gly-OH, Boc-Ala-OH, Boc-Tyr(Bzl)-OH and Boc-Glu(OBzl)-OH were prepared as described by the method of Schnabel. ${ }^{20}$ The resin used was Bio-Beads S-X2, 200-400 mesh, Bio-Rad Laboratories, Richmond, Calif., chloromethylated according to the method of Feinberg and Merrifield. ${ }^{21}$ The degree of substitution was determined by Volhard titration 22 to $1.10 \mathrm{meq} \mathrm{Cl}$ per gram of chloromethylated resin. The chloromethylated resin was esterified according to Losse et al. ${ }^{23}$ resulting in $0.35 \mathrm{meq}$ glycine per gram of substituted resin. For the peptides 2 and 3 (Table 1 ), a resin $(0.70 \mathrm{meq} \mathrm{Cl} / \mathrm{g})$ prepared by the method of Gisin ${ }^{24}$ with a substitution degree of $0.50 \mathrm{meq}$ glycine per gram of substituted resin was used. Sephadex G-10 and DEAE-Sephadex A-25 were obtained from Pharmacia, Uppsala.

Amino acid analysis was carried out after hydrolysis of the peptides in evacuated, sealed vials at $110^{\circ} \mathrm{C}$ in $6 \mathrm{M}$ hydrochloric acid for $24 \mathrm{~h}$, using an updated Beckmann Model 120C Amino Acid Analyzer.

Mass spectrometric analyses. The mass spectra were recorded on a Perkin Elmer 270 Mass Spectrometer with a resolution of approximately 1000 . The ionizing energy was $70 \mathrm{eV}$, and the temperature of the ion source $150^{\circ} \mathrm{C}$. Samples of esterified and permethylated peptides were introduced directly into the ion source. Spectra were recorded at probe temperatures between 150 and $250^{\circ} \mathrm{C}$.

High voltage electrophoresis. Electrophoresis was carried out on Whatmann 3MM paper, equilibrated with $0.01 \mathrm{M}$ phosphate buffer, $\mathrm{pH} 6.5$, and $0.15 \mathrm{M}$ with respect to citric acid. A Shandon, Metal Plate Cooled, High Voltage Apparatus was used. Voltage gradient $40 \mathrm{~V} / \mathrm{cm}$ for $2 \mathrm{~h}$. Peptides were visualized using a $1 \%$ $(\mathrm{w} / \mathrm{v})$ solution of ninhydrine in acetone. To each $1000 \mathrm{ml}$ portion was added $100 \mathrm{ml}$ of aqueous $1 \%$ (w/v) cadmium acetate and $50 \mathrm{ml}$ of glacial acetic acid before use.

Synthesis. Five heptapeptides with the general formula H-Tyr-X-X-X-Ala-Ala-Gly-OH (X = Tyr or Glu) were prepared (Table 1). The syntheses were carried out using an automated peptide synthesizer as described by Brunfeldt et al..$^{25} \mathrm{~A}$ siliconized glass reactor rendered, however, circulation of the reaction mixture superfluous. Potentiometric titrations of fre $\theta \alpha$-amino groups ${ }^{28}$ were carried out using $0.20 \mathrm{M}$ perchloric acid in glacial acetic acid. Titrations were initiated and stopped manually. The titration equipment consisted of a TTTle titrator and an ABUl autoburette $(25 \mathrm{ml})$ from Radiometer, Copenhagen. The initial potential was approximately $-290 \mathrm{mV}$, and the preset endpoint $\mathbf{- 4 8 2} \mathrm{mV} \cdot{ }^{26}$ The delayed shut-off time was $5 \mathrm{~min}$ (unless otherwise stated), the proportional band 0.05 and the burette speed 4.

The standard synthetic schedule (after 3-5 initial cycles of titration of Boc-Gly-O-resin, to ensure a reliable base line) was as shown in Table 2: deblocking (II), titration (I), coupling of Boc-amino acid derivative (III), titration (I), etc. Each synthesis was carried out using $10 \mathrm{~g}$ of Boc-Gly-O-resin. Boc-amino acids and $N, N^{\prime}$-dicyclohexylcarbodiimide were 
Table 2. Synthetic schedule. Reagents, amounts and time of treatments are listed for cycles of titration (I), deblocking (II) and coupling (III).

\begin{tabular}{|c|c|c|c|c|c|}
\hline I & II & III & Solvents and reagents & Volume/ml & Time/mi \\
\hline 1 & $\begin{array}{l}0 \\
0 \\
2(0)^{a} \\
0 \\
1 \\
1 \\
3(0)^{a} \\
0 \\
0 \\
0 \\
3(6)^{a} \\
0\end{array}$ & $\begin{array}{l}1 \\
5 \\
0 \\
0 \\
0 \\
0 \\
0 \\
1(0)^{b} \\
1(1)^{b} \\
0(1)^{b} \\
3 \\
6\end{array}$ & $\begin{array}{l}\mathrm{CH}_{2} \mathrm{Cl}_{2}+\left(\mathrm{C}_{2} \mathrm{H}_{5}\right)_{3} \mathrm{~N}+\mathrm{CH}_{2} \mathrm{Cl}_{2} \\
\mathrm{CH}_{2} \mathrm{Cl}_{2} \\
\mathrm{CH}_{3} \mathrm{COOH} \\
\mathrm{CH}_{3} \mathrm{COOH}+\mathrm{CH}_{2} \mathrm{Cl}_{2} \\
1 \mathrm{M} \mathrm{HCl} \mathrm{in} \mathrm{CH}_{3} \mathrm{COOH} \\
1 \mathrm{M} \mathrm{HCl} \mathrm{in} \mathrm{CH}_{3} \mathrm{COOH} \\
\mathrm{CH} \mathrm{H}_{3} \mathrm{COOH} \\
\mathrm{Boc} \text {-amino acid } / \mathrm{CH}_{2} \mathrm{Cl}_{2} \\
N, N^{\prime} \text {-diclyclohexylcarbodiimide } / \mathrm{CH}_{2} \mathrm{Cl}_{2} \\
\text { Boc-amino acid } / \mathrm{CH}_{2} \mathrm{Cl}_{2} \\
\mathrm{CH}_{2} \mathrm{Cl}_{2} \\
\mathrm{C}_{2} \mathrm{H}_{5} \mathrm{OH}\end{array}$ & $\begin{array}{l}40+5+40 \\
80 \\
80 \\
40+40 \\
80 \\
80 \\
80 \\
40 \\
40 \\
40 \\
80 \\
80\end{array}$ & $\begin{array}{l}\mathbf{5} \\
\mathbf{5} \\
\mathbf{5} \\
\text { titration } \\
\mathbf{5} \\
\mathbf{3 0} \\
\mathbf{5} \\
\mathbf{3 0} \\
\mathbf{2 4 0}(30)^{b} \\
\mathbf{2 4 0} \\
\mathbf{5} \\
\mathbf{5}\end{array}$ \\
\hline
\end{tabular}

a Modified program for the deprotection of $N$-terminal Boc-Glu-(OBzl)-, omitting titrations and acetic acid treatment. ${ }^{b}$ When forming the tripeptide, $N, N^{\prime}$-dicyclohexylcarbodiimide was added before the Bocamino acid derivative, to prevent the formation of a diketopiperazine. ${ }^{38}$

used in three-fold excess. A modified synthetic procedure (Table 2) omitting glacial acetic acid from all solvents in contact with $N$-terminal $N$-deprotected glutamic acid $\gamma$-benzyl ester residues (except for the deblocking reagent itself: $1 \mathrm{M}$ hydrogen chloride in glacial acetic acid), was used where indicated (see Results and Discussion for details). In the modified synthetic procedure perchloric acid titrations were, likewise, omitted at the critical steps mentioned.

Cleavage from the resin. After completion of the requested peptide sequence (including deblocking of the $N$-terminal $\alpha$-amino groups and titration), the peptide-resin was dried and suspended in trifluoroacetic acid-anisole (9:1, $v / v)$. Cleavage of the peptide from the resin was achieved by treatment of the suspended peptide-resin with bromine-free hydrogen bromide for $2 \times 60 \mathrm{~min}$ at room temperature. The resin was washed with trifluoroacetic acid and the combined filtrates were evaporated at reduced pressure (temp. $<30^{\circ} \mathrm{C}$ ). The crude, dry peptide was dissolved in $N, N$-dimethylformamide and precipitated with diethyl ether, filtrated, air dried and dried in vacuo over KOH. Yields of the crude peptide preparation ranged between 75 and $89 \%$, based on the degree of substitution of the Boc-Gly-O-resin.

$D E A E$-Sephadex fractionation. The crude peptides were filtrated on Sephadex G-10 $(1.5 \times 120 \mathrm{~cm}$ columns) in $0.2 \mathrm{M}$ ammonia, evaporated, dried and dissolved in $0.01 \mathrm{M}$ phosphate buffer, pH 7.0. Between 100 and $200 \mathrm{mg}$ of Sephadex-fractionated peptides were applied to a DEAE-Sephadex (A-25) column $\left(\begin{array}{ll}1.5 \times 30 & \mathrm{~cm}\end{array}\right)$, equilibrated with $0.01 \mathrm{M}$ phosphate buffer, pH 7.0. After an initial elution with phosphate buffer $(150-200 \mathrm{ml})$, a linear gradient (2000 ml total) to $0.5 \mathrm{M}$ $\mathrm{NaCl}$ in $0.01 \mathrm{M}$ phosphate buffer, $\mathrm{pH} 7.0$, was developed using a three-channel peristaltic pump (Pharmacia P-3). An identical column was run in parallel, feeding the reference cell of an Uvicord III UV-Absorptiometer (LKB). Absorbance of the eluate was monitored at 206 and $280 \mathrm{~nm}$. The $206 \mathrm{~nm}$ baseline could, however, only be maintained to about $0.1 \mathrm{M}$ $\mathrm{NaCl}$, before drifting downscale, allowing only a rough estimate of the $206 \mathrm{~nm}$ peak height. Absorbances are therefore only indicated at $280 \mathrm{~nm}$. The $206 \mathrm{~nm}$ absorbance demonstrated an additional heterogeneity of the peptide preparations, not further analyzed (see Ref. 6 for examples of the $206 \mathrm{~nm}$ absorbance in DEAE-Sephadex ion exchange chromatography of crude preparations of solid-phase synthesized oligopeptides).

Fractions representing $280 \mathrm{~nm}$ peaks were collected, evaporated, desalted on a bovine serum albumine-saturated Sephadex G-10 (1.5 × $120 \mathrm{~cm}$ ) column in $0.2 \mathrm{M}$ ammonia, evaporated, and freeze-dried. After desalting, the required peptides proved homogeneous by high voltage electrophoresis. Yields in the desalting step were estimated from the absorbance before and after Sephadex G-10 passage. The recovery was 45-70\%; lowest for peptides with several aromatic residues. The peptides were identified by amino acid analysis, in some cases supplemented by mass spectrometric sequence determination. ${ }^{27}$

Acta Chem. Scand. B 33 (1979) No. 9 


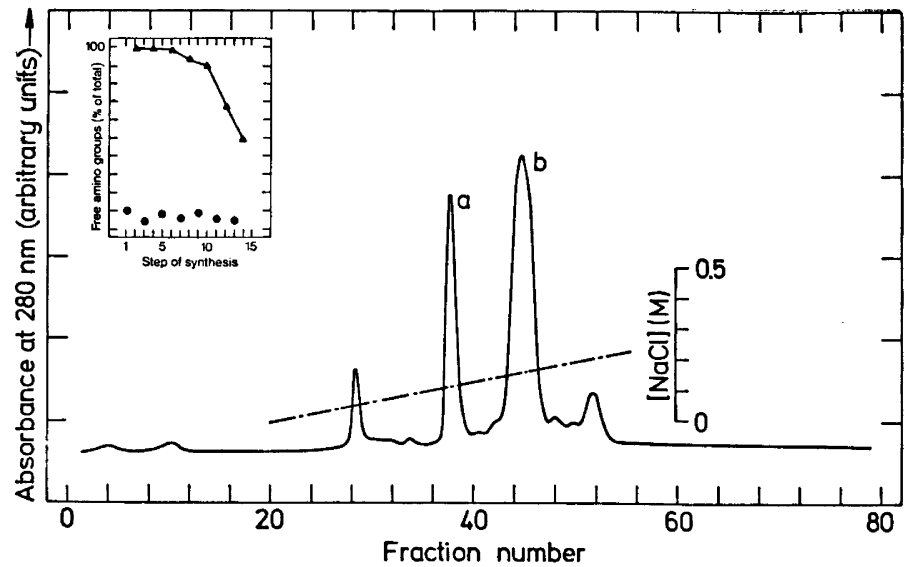

Fig. 1. DEAE-Sephadex ion exhange chromatogram of H-Tyr-Glu-Glu-Tyr-Ala-Ala-Gly-OH (1) synthesized according to the unmodified program of Table 2 . Inserted is the percentage of free amino groups for each synthetic step (1:Boc-Gly-O-resin; 2: H-Gly-O-resin; 3: Boc-Ala-Gly-O-resin; etc.) as determined by potentiometric perchloric acid titration (protected $(\mathbf{O})$, and deprotected $(\Lambda)$ $N$-terminal).

Amino acid analysis (Gly:Ala:Glu:Tyr) identified peak (b) as representing the expected peptide althnugh deficient in tyrosine (see text) ((b), 1.00:2.07:2.07:1.70).

Peak a was devoid of one tyrosine and one glutamic acid residue ((a), 1.00:2.07:1.08:1.04).

\section{RESULTS}

In the synthesis of H-Tyr-Glu-Glu-Tyr-AlaAla-Gly-OH (1), according to the unmodified program of Table 2, a considerable decrease in the number of titrable groups was observed in steps 12 and 14 of the synthesis (Fig. 1). Although $90 \%$ of the reactive peptide chains were still present in step 10, H-Glu(OBzl)Tyr(Bzl)-Ala-Ala-Gly-O-resin, the number drastically decreased after this step of the synthesis: In step 12, H-Glu(OBzl)-Glu(OBzl)$\operatorname{Tyr}(\mathrm{Bzl})$-Ala-Ala-Gly-O-resin, approximately $65 \%$ were left, and when the last residue, tyrosine, had been successively coupled and deblocked, less than $50 \%$ of the free $\alpha$-amino groups originally present could be detected by potentiometric titration.

To test whether the observed decrease was due to incomplete removal of Boc-groups, repeated deblockings were carried out (not shown). Such deblockings resulted inevitably, however, in a further (slight) decrease in the number of titrable groups (see Fig. 5, and Fig. 6, insertion B).

DEAE-Sephadex chromatographic analysis of the peptide preparation, obtained after cleavage of the peptide from the solid support, showed two major by-products (Fig. 1). The first one (a) was found, according to amino acid analysis to be devoid of both a tyrosyl and a glutamyl residue (Gly, 1.00; Ala, 2.07; Glu, 1.08; Tyr, 1.04). The peptide was negative to ninhydrine, and was identified as < Glu-TyrAla-Ala-Gly-OH by mass spectrometry, i.e. as a peptide truncated in step 10 of the synthesis.

The main peak (b) of Fig. 1 was slightly deficient in tyrosine, according to amino acid analysis (Gly, 1.00; Ala, 2.07; Glu, 2.07; Tyr, 1.70). A finding probably indicating the presence of an unresolved mixture of two peptides, namely the requested sequence, H-Tyr-Glu-Glu-Tyr-Ala-Ala-Gly-OH (1), and a truncated peptide, < Glu-Glu-Tyr-Ala-Ala-Gly$\mathrm{OH}$, which had been terminated in step 12, after the addition of the second glutamic acid residue (not analyzed).

The reason why the proposed truncations in steps 10 and 12 of the synthesis are observed in steps 12 and 14 respectively by potentiometric perchloric acid titration may be explained as shown in Fig. 2. The side reaction forming pyroglutamyl is supposed to be slow. Thus, if titrations are performed immediately after deblocking, e.g. within 60-90 min (as in Fig. 1), the decrease in titration values caused by 


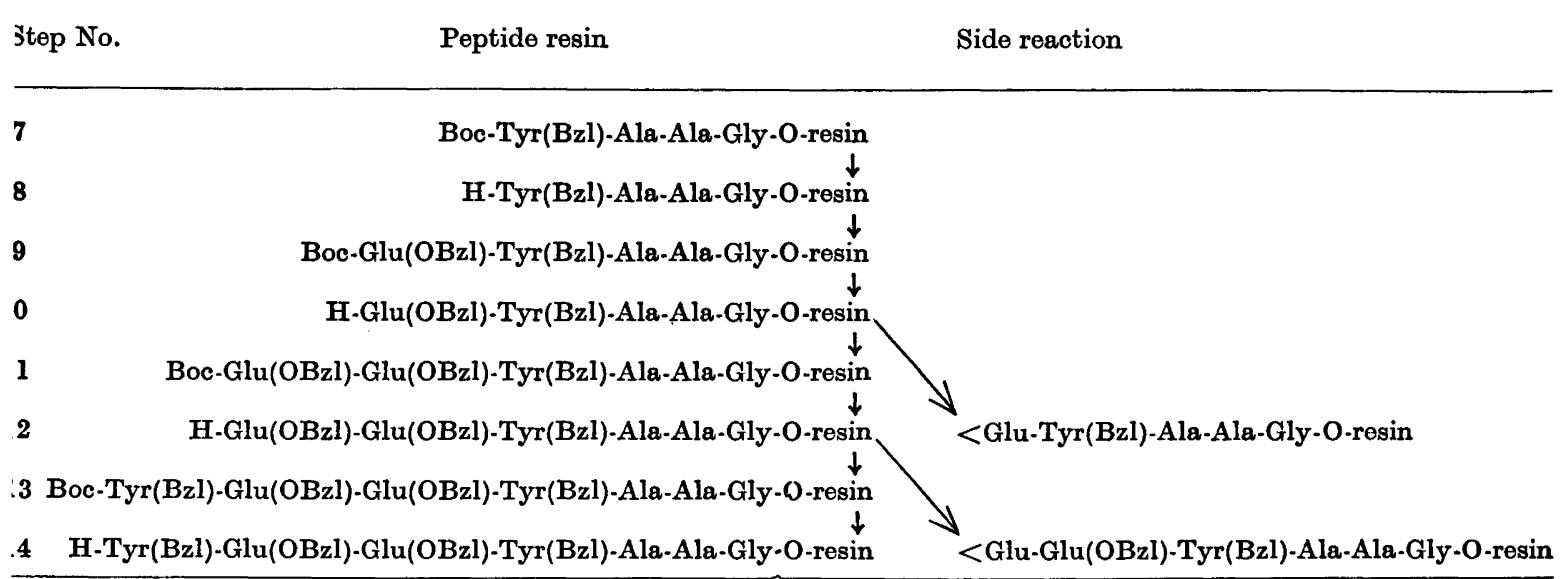

Fig. 2. Partial reaction scheme of the synthesis of H-Tyr-Glu-Glu-Tyr-Ala-Ala-Gly-OH (1) according to the unmodified synthetic schedule of Table 2 . Side reactions are indicated in steps 10 and 12 of the synthesis, forming $N$-terminal pyroglutamic acid residues, and thus terminating the peptide chain at these steps. Depending on the rate of reaction and the time elapsed between deprotection and titration the termination of chain growth may, however, be observed in steps 12 and 14 of the synthesis as observed in Fig. 1 (also compare this scheme with the results of Fig. 5).

pyroglutamylformation in steps 10 and 12 will be associated with steps 12 and 14, respectively. Alternatively, if several hours are allowed to pass before titration, the decrease will be found at the expected steps of the synthesis. This possibility is further analyzed in the following (see Fig. 5, and text).

Studies by Beyermann et al..$^{28}$ on the formation of pyroglutamyl from $N$-terminal glutaminyl pointed to acetic acid as the main cause of this side reaction. Results from these studies prompted us to modify our synthetic schedule in order to test, whether acetic acid might, likewise, be the cause of the formation of pyroglutamyl from $N$-terminal glutamyl $\gamma$-benzyl ester.

The synthesis of H-Tyr-Glu-Glu-Tyr-Ala-AlaGly-OH (1) was therefore repeated, using the modified program of Table 2, i.e., avoiding acetic acid at steps in the synthesis, where $N$-terminal glutamyl $\gamma$-benzyl ester is found $N$-deprotected. Unfortunately, as a consequence of this modification, we, furthermore, had to cancel the titrations at these critical steps. An over-all result of the modified synthetic procedure in terms of titration values was, however, believed to be obtainable at a following step, where tyrosine had been successively coupled and deblocked. The $\alpha$-amino deblocking reagent, $1 \mathrm{M}$ hydrogen chloride in acetic acid, was retained, catalyzing only weakly $(1 \%$ in $70 \mathrm{~h}$ ) the formation of pyroglutamyl. ${ }^{28}$ Modified synthetic procedures are indicated by dashed lines in the insertions of Figs. 3, 6 and 7.

The results of the modified synthesis of 1 are shown in Fig. 3. The over-all decrease in the number of titrable groups was approximately $30 \%$; an improvement as compared to the unmodified synthesis (Fig. 1), although not satisfactory.

The DEAE-chromatogram of the free peptide preparation showed two major by-products (Fig. 3). The first one (b) was the requested peptide (Gly, 1.00; Ala, 2.03; Glu, 2.00; Tyr, 1.98), whereas the second peak (c), according to amino acid analysis, was devoid of one tyrosine residue (Gly, 1.00; Ala, 2.04; Glu, 1.99; Tyr, 0.98). To explain this finding, a truncation of the peptide chain after the addition of the second glutamic acid residue was, of course, a possibility, although the reason why pyroglutamyl should not be formed also at the step of the first glutamic acid residue was unclear. Furthermore, the position of peak (c) relative

Acta Chem. Scand. B 33 (1979) No. 9 


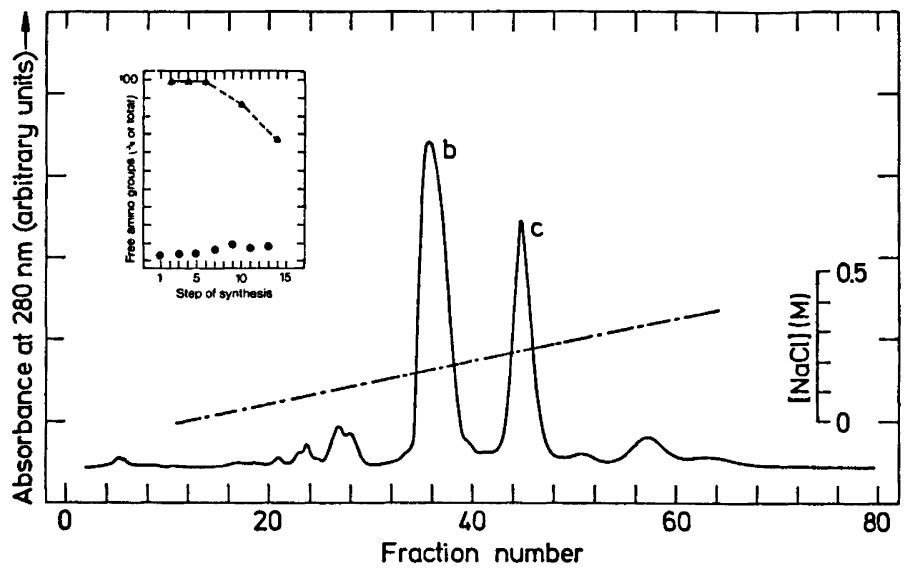

Fig. 3. DEAE-Sephadex chromatography of H-Tyr-Glu-Glu-Tyr-Ala-Ala-Gly-OH (1), synthesized according to the modified schedule of Table 2 . In steps 10 and 12 of the synthesis, i.e. in the presence of $\alpha$-amino deprotected glutamic acid residues, acetic acid was avoided (see text). Amino acid analysis (Gly:Ala:Glu:Tyr) revealed peak (b) to represent the expected peptide ((b), 1.00:2.03:2.00: 1.98), whereas the peptide in peak (c) apparently was devoid of one tyrosine residue ((c), 1.00:2.04: 1.99:0.98).

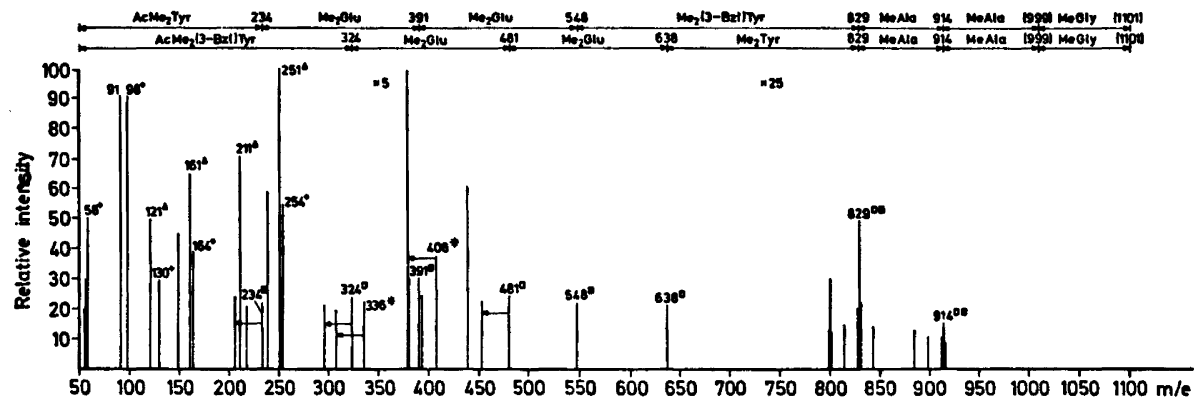

Fig. 4. Mass spectrum of an acetylated and permethylated specimen obtained from peak (c) (Fig. 3). Fragments $(+), m / e 58,98,130,164$ and 254 representing amino acid residues Ala, < Glu, Glu, Tyr and (3-Bzl)Tyr respectively, together with fragments $(\triangle), m / e 251,211$, and 161, 121 representing (3-Bzl)Tyr and Tyr, respectively, depict the presence of both Tyr and (3-Bzl)Tyr. The following two series of sequence peaks demonstrate the presence of two different peptides, both of which 3benzylated at only one residue: H-(3-Bzl)Tyr-Glu-Glu-Tyr-Ala-Ala-Gly-OH ( $\square$ ), m/e 324, 481, 638, 829, 914, (999, 1101 (not seen)) and H-Tyr-Glu-Glu-(3-Bzl)Tyr-Ala-Ala-Gly-OH (a), m/e 234, 391,548 , while peaks at $m / e 829,914,(999,1101$ (not seen)) are identical to peaks ascribed to the former component. The 3-benzylation of Tyr, at only one of the two possible positions in the heptapeptide, is further supported by the presence of peaks corresponding to cleavages typical of aromatic residues $\left({ }^{*}\right), m / e \quad 336,308$ and 408,380 , indicative of sequences (3-Bzl)Tyr-Ala and (3Bzl)Tyr-Glu, respectively. Arrow indicates loss of $\mathrm{CO}$ (mass 28). Peaks at m/e 149 and 239 are ascribed to resin additives, normally present as artefacts in preparations of solid-phase peptides. Peak $m / e 843$ and other peaks appearing 14 mass units above a parent peak at higher $m / e$ values in the spectrum are ascribed to partial $\gamma$-C-methylation of Glu. Peaks at $m / e$ 440, 800 and 885 have not been identified.

to peptide 1 of peak (b), and the fact that peak (c) was positive to ninhydrine ruled out this possibility.

Mass spectrometric analysis showed peak (c) in Fig. 3 to be a mixture of two peptides, both of which heptapeptides, however, with the tyrosine residues in position 4 and 7 of the peptide, respectively, substituted with 3 . benzyltyrosine (Fig. 4). The $\mathrm{O} \rightarrow \mathrm{C}$ rearrangement of the $O$-protecting benzyl group of 
tyrosine resulting in the formation of 3-benzyltyrosine has been described in detail by Ericson and Merrifield ${ }^{17}$ and a number of procedures to overcome this side reaction have been proposed (see discussion). Up to $40 \mathrm{~mol} \%$ of the rearrang. ed residue has been reported ${ }^{17}$ depending on the clevage procedure applied. In our study, 21-36 mol \% of peptides $1-5$ were observed with one of the tyrosine residues replaced by 3-benzyltyrosine.

The absence of any further, major peaks in the DEAE-chromatogram of the modified preparation of 1 (Fig. 3) indicates that truncation of the peptide chain due to pyroglutamyl formation had indeed been largely eliminated by the modified synthetic schedule applied.

However, according to this interpretation one major question was left: When the apparent decrease in the number of titrable groups in the modified synthesis of 1 (Fig. 3) could not be ascribed to $N$-terminal pyroglutamyl truncation of the peptide chain, what was then the reason for the $30 \%$ decrease actually observed? To study this phenomenon in more detail the synthesis of 1 was repeated using the unmodified procedure of Table 2. Each deblocking of $N$-terminal tyrosine and glutamic acid residues was, however, duplicated, and three titrations at different time intervals were performed after each deblocking.

Two major results were obtained (Fig. 5): First, pyroglutamyl formation appears to be slow. Repeated titrations within 60-90 min did not change the results significantly. However, a prolonged (overnight) exposure to dichloromethane of the neutralized $N$-deprotected $N$-terminal glutamyl $\gamma$-benzyl ester seemed to promote this side reaction (titration values indicated by arrows in Fig. 5). When titrations were done up to $36 \mathrm{~h}$ after the deblocking, the expected decrease in the number of titrable groups could thus be observed in steps 10 and 12 of the synthesis (i.e., at steps where $N$. terminal pyroglutamyl is actually formed). The deblocking reagent, $1 \mathrm{M}$ hydrogen chloride in acetic acid, did only affect the degree of cyclization to a minor degree, as can be seen if titration series (a) and (b) of Fig. 5 are compared (b indicates titration values after a repeated deblocking). Second, potentiometric titrations at step 14, H-Tyr(Bzl)-Glu(OBzl)-Glu-(OBzl)$\operatorname{Tyr}(\mathrm{Bzl})$-Ala-Ala-Gly-O-resin, revealed an un-

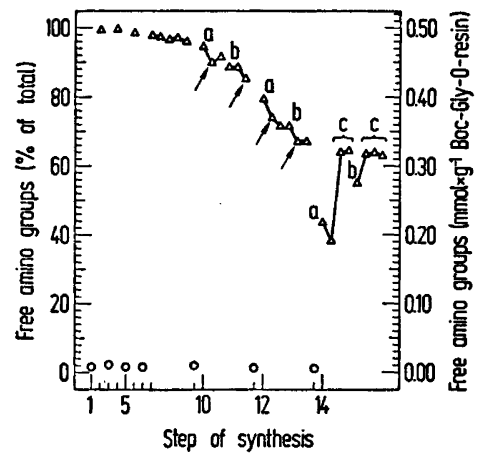

Fig. 5. Percentage of reactive peptide chains during the synthesis of H-Tyr-Glu-Glu-Tyr-AlaAla-Gly-OH (1), by the unmodified procedure of Table 2, as determined by potentiometric titrations. In steps 10, 12 and 14 of the synthesis $(N$-deprotected first and second glutamic acid, and last tyrosine residues, respectively) repeated deblockings were applied (a: titration values after first deblocking, b: titration values after second deblocking). Three successive titrations were done for each synthetic step. Arrows in steps 10 and 12 indicate values obtained when the peptide-resin had been exposed to dichloromethane overnight.

In step 14, the delayed shut-off time of the automatic titrator was changed to $\infty$ because of an extremely slow reaction (indicated by c).

expected, apparent further decrease of approximately $20 \%$ in the number of $\alpha$-amino groups. Recordings of potential versus time during titration (not shown) indicated that the titration had not been terminated at the delayed shut-off time of the automatic titrator $(5 \mathrm{~min})$ routinely used. Thus, if the shut-off time was changed (to $\infty$ ) the titration could be terminated at the expected titration value, i.e. at the level of the preceding step, after some $5-8 \mathrm{~h}$ of titration (with a terminating shut-off time of $35-40 \mathrm{~min}$ ). These titration values are indicated (c) in Fig. 5.

However, the syntheses of peptides $2-5$ (Table 1) were accomplished before the unexpected slow titration in the last steps of synthesis of 1 was fully elucidated. Only in the case of 2 , and only at the last step of the synthesis, was a repetition of the titration with a delayed shut-off time of $\infty$ possible. Here again, however, a slow reaction was depicted, indicating that this mode of titration may be a general phenomenon among the series of 


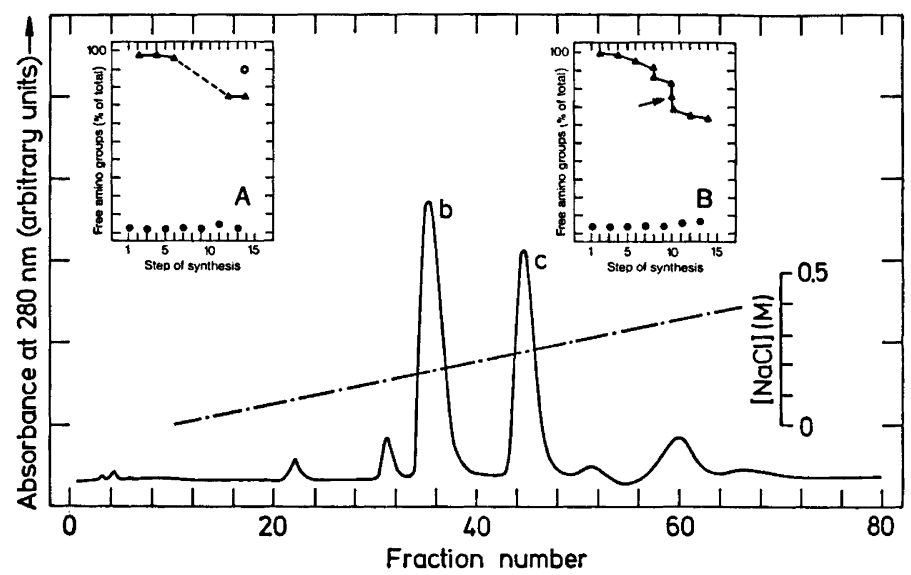

Fig. 6. DEAE-Sephadex chromatography of H-Tyr-Tyr-Glu-Glu-Ala-Ala-Gly-OH (2) synthesized using the modified program of Table 2 in steps 8 and 10 where unprotected $N$-terminal glutamic acid residues were present.

Amino acid analysis (Gly:Ala:Glu:Tyr) showed peak (b) to represent the desired peptide ((b), 1.00:2.05:2.05:1.98) whereas the peptide in peak (c) was devoid of one tyrosine residue ((c), 1.00: 2.05:2.05:0.98). Titration values during synthesis are shown in insertion $A$. The open circle (O), shows the titration value of step 14 in the synthesis, when the delayed shut-off time of the autotitrator was changed to $\infty$. Insertion B shows the results of a synthesis of the same peptide 2 using, however, the unmodified synthetic program of Table 2 in steps 8 and 10. A repeated deblocking was performed at step 10 (arrow). This peptide was not cleaved from the resin.

peptides synthesized. Thus, the titration values of peptides 2-5 may be of limited value as regards coupling yields in the last steps of the syntheses. In accordance, no indication of major amounts of pyroglutamyl terminated peptides was observed in the DEAE-chromatograms of peptides $2-5$.

The synthesis of H-Tyr-Tyr-Glu-Glu-Ala-AlaGly-OH (2) was carried out twice. First the unmodified program of Table 2 was applied. Potentiometric titrations (insertion B of Fig. 6) showed the expected decrease in the number of $\alpha$-amino groups assigned to pyroglutamyl formation (over-all yield, $63 \%$ ). In order to test the efficiency of the deblocking procedure, a repeated deblocking (arrow) was performed at step 10 of the synthesis, H-Glu(OBzl) Glu(OBzl)-Ala-Ala-Gly-O-resin, however, resulting only in a further decrease in the number of reactive peptide chains. The peptide was not cleaved from the solid support.

The synthesis of 2 was repeated using the modified procedure of Table 2 in steps 8 and 10 of the synthesis. Titration values are shown in insertion A of Fig. 6. The observed over-all decrease (approximately $25 \%$ ) in the titration values obtained is according to the results earlier discussed (Fig. 5) now largely ascribed to non-terminated potentiometric titrations at steps 12 and 14. A repeated titration at step 14 of the synthesis, using a delayed shut-off time of $\infty$, actually resulted in an over-all decrease in the number of titrable groups of only $10 \%$ (indicated by an open circle in insertion $\mathrm{A}$ of Fig. 6).

The main peak (b) of the chromatogram represented the required peptide, H-Tyr-TyrGlu-Glu-Ala-Ala-Gly-OH (2) (Gly, 1.00; Ala, 2.05; Glu, 2.05; Tyr, 1.98). Peak c was devoid of one tyrosine residue according to the amino acid analysis, implying that one of the two tyrosine residues had been 3-benzylated during cleavage (Gly, 1.00; Ala, 2.05; Glu, 2.05; Tyr, 0.98).

In the synthesis of peptides $3-5$, the modified synthetic procedure was applied in all critical steps (i.e., where the glutamic acid $\gamma$-benzyl ester residue was found $N$-deprotected). The DEAE chromatogram of H-Tyr-Glu-Tyr-GluAla-Ala-Gly-OH (3) (Fig. 7), indicated that the $N$-terminal pyroglutamyl truncation of the peptide chain had actually largely been abrogated. The major peak (b) of Fig. 7 


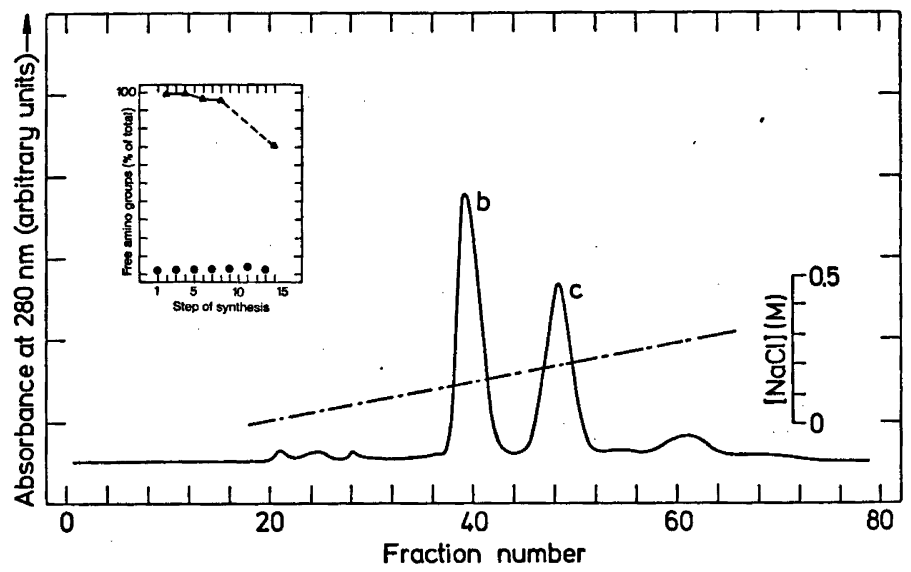

Fig. 7. DEAE-Sephadex chromatography of H-Tyr-Glu-Tyr-Glu-Ala-Ala-Gly-OH (3) synthesized using the modified program of Table 2 in steps 8 and 12.

Amino acid analysis (Gly:Ala:Glu:Tyr) showed peak (b) to represent the required peptide ((b), 1.00:2.00:1.99:1.91), whereas the peptide in peak (c) was devoid of one tyrosine residue ((c), 1.00: $2.08: 2.02: 1.00)$.

represented the required sequence (Gly, 1.00; Ala, 2.00; Glu, 1.99; Tyr, 1.91), whereas peak c was devoid of one tyrosine residue according to amino acid analysis (Gly, 1.00; Ala, 2.08; Glu, 2.02; Tyr, 1.00). Thus, the decrease in the titration values observed must be assigned primarily to nonterminated titrations in the last steps of the synthesis, caused by extraordinary slow reactions.

Perchloric acid titrations in the synthesis of H-Tyr-Glu-Tyr-Tyr-Ala-Ala-Gly-OH (4), likewise, revealed an apparent, total decrease of more than $40 \%$ of the titrable groups. Although the DEAE-chromatogram (not shown) of the peptide preparation was complicated by a number of additional (minor) peaks appearing before the two major ones (compare with Fig. 7), it seemed again plausible to assign the observed decrease in titration values primarily to nonterminated titrations, and thus to extraordinary slow reactions. The major peak (b) was identified by amino acid analysis to represent the required peptide (Gly, 1.00; Ala, 1.99; Glu, 1.01; Tyr, 2.94), whereas the ninhydrine positive peak (c) according to amino acid analysis was devoid of one tyrosine residue, (Gly, 1.00; Ala, 1.97; Glu, 0.90; Tyr, 1.97), probably associated with 3-benzylation of one of the three tyrosine residues present (not analyzed).

The chromatogram of the crude preparation of H-Tyr-Glu-Glu-Glu-Ala-Ala-Gly-OH (5) was similar to that of 3 shown in Fig. 7, i.e. depicting only two major peaks ((b) and (c)) both of which were ninhydrine-positive. Peak (b) was identified as 5 by amino acid analysis (Gly, 1.00; Ala, 2.06; Glu, 3.05; Tyr, 0.97) and mass spectrometric analysis (not shown). Peak (c) was assigned the sequence H-(3-Bzl)Tyr-GluGlu-Glu-Ala-Ala-Gly-OH on the basis of amino acid analysis (Gly, 1.00; Ala, 2.02; Glu, 3.04; Tyr, trace), the absorbance at $280 \mathrm{~nm}$, and the ninhydrine-positive reaction. The decrease in the titration values (total of $30 \%$ ) during the synthesis, thus, cannot be assigned to $N$ terminal pyroglutamyl formation despite the fact that the peptide 5 contains not less than three consecutive glutamic acid residues, but must again be due to an extraordinary slow titration of the $N$-deprotected resin-bound peptide derivative in the last step of the synthesis.

\section{DISCUSSION}

Incomplete coupling has been associated with $N$-terminal pyroglutamyl formation by $N$-terminal glutaminyl residues during solidphase peptide synthesis. This problem has in some studies been controlled by replacing $1 \mathrm{M}$ hydrogen chloride in acid as the deblocking

Acta Chem. Scand. B 33 (1979) No. 9 
reagent with trifluoroacetic acid in dichloromethane. ${ }^{20,30}$ Studies by Beyermann et al..$^{28}$ however, pointed to acetic acid as the main cause of this side reaction, whereas $1 \mathrm{M}$ hydrogen chloride in acetic produced less than $1 \%$ of chain termination in $70 \mathrm{~h}$.

Low yields in the synthesis of another number of peptides have equivalently been attributed to chain terminating side reactions involving glutamyl residues. ${ }^{31,32}$ Polzhofer and Ney ${ }^{12}$ observed a drastic decrease in the number of reactive resin-bound peptide chains in the synthesis of an octadecapeptide related to $\alpha$-casein containing two series of three glutamic acid residues. Feinberg and Merrifield ${ }^{13}$ suggested that the associated chain termination might be due to a nucleophilic displacement of the protecting $\gamma$-benzyl ester by $\alpha$-amino groups of the glutamyl residue, forming $N$-terminal pyroglutamyl.

In our study the formation of $N$-terminal pyroglutamyl was observed as a decrease in the number of titrable $\alpha$-amino groups in critical steps of the synthesis, in which $N$. terminal $\gamma$-benzyl glutamyl was found $N$. deprotected. The decrease was associated with the formation of truncated peptides which could be isolated be ion exchange chromatography. These by-products were eliminated when the standard synthetic schedule was slightly modified so that acetic acid was removed from the critical steps of the synthesis. Hydrogen chloride in acetic acid (I M) as the cleavage reagent did not promote pyroglutamyl formation to any significant extent. The modified synthetic schedule was, however, additionally characterized by having $N$. deprotected $\gamma$-benzyl glutamyl residues exposed to solvent in a considerably shorter time, than the standard schedule. Thus, although it proved possible to suppress pyroglutamyl formation, no single reason for this side reaction has conclusively been established. In fact, certain observations (Fig. 5) additionally point to a prolonged exposure to dichloromethane as a main reason for the chain truncation observed.

Glutamyl residues are involved in another side reaction which is, however, associated with the cleavage reaction: Bonora et al..$^{15}$ observed in the synthesis of the peptides (H-(Glu $)_{n}$ $\mathrm{Phe}\left(\mathrm{NO}_{2}\right)$-Phe-OH $(n=1-4)$ that the number of by-products increased with the number of glutamic acid residues. Less complex mixtures were, however, formed when hydrogen fluorideanisole was replaced as the cleavage reagent with hydrogen bromide in trifluroacetic acid. Sano and Kawanishi ${ }^{14,16}$ identified $\gamma$-anisylation of the glutamyl residue and an associated rearrangement to 4-p-methoxybenzoyl-2-aminobutyl as the main by-products. Feinberg and Merrifield ${ }^{13}$ confirmed these findings and identified an additional by-product as a truncated peptide formed by the cyclization of the 4-p-methoxybenzoyl-2-amino-butyl residue to $N$-terminal 2-p-methoxyphenyl-1pyrroline-5-carbonyl. Neither of these side reactions were, however, observed to any significant degree (in accordance with our results) when hydrogen bromide/anisole-trifluoroacetic acid $(12.5 \%, v / v)$ was used as the cleaving reagent.

The formation of 3-benzyltyrosyl containing peptides due to an $\mathrm{O} \rightarrow \mathrm{C}$ rearrangement of the $O$-protecting group of tyrosine is now well described. ${ }^{17-19}$

A number of procedures to overcome this side reaction have been proposed: An alternative application of the 2,6-dichlorobenzyl group resulted in $5 \%$ rearrangement, ${ }^{17}$ whereas other protecting groups, e.g. the cyclohexyl group, produced less than $0.3 \%$ of the rearranged product under standard cleaving conditions with hydrogen fluoride $\left(0^{\circ} \mathrm{C}, 30 \mathrm{~min}\right) .^{18} \mathrm{It}$ showed possible to suppress the rearrangement of the $O$-benzyl group by using hydrogen bromide-acetic ${ }^{33}$ as the cleaving reagent. ${ }^{5,19,34,35}$ Replacing acetic acid with phenol and $p$-cresol resulted in about $1 \%$ rearranged tyrosyl residues. ${ }^{10}$ Yonesawa et al..$^{36}$ retained hydrogen fluoride as the cleaving reagent, but added large amounts of anisole and phenol in dichloromethane to the reaction mixture.

In our study by-products containing a 3 benzyltyrosine residue were separated from the main product by ion exchange chromatography in yields of $21-36 \mathrm{~mol} \%$ (comparable to the figures reported by Erickson and Merrifield ${ }^{17}$ ). No attempts were made to suppress the side reaction by any of the abovementioned procedures.

A significantly delayed mode of the potentiometric titrations was realized for certain peptide sequences when an apparent decrease in the number of titrable groups was found to be due 
to a premature shut-off the titrator. This extreme mode of titration was studied in more detail for one of the peptides synthesized. The time used for one titration was in this case 6-8 $\mathrm{h}$ as compared to the normal $1-2 \mathrm{~h}$. A more detailed inspection of the potential versus time recordings obtained during titration revealed that titrations in this and in another number of cases had not been terminated at the standard shut-off time $(5 \mathrm{~min})$ used. The reason for this delay has been tentatively proposed to be conformational properties of the protected peptide chains. Only little is, however, known about this apparently important feature in solid-phase peptide synthesis, whereas some initial studies have been presented using a solubilizing polymer support. ${ }^{37}$

Acknowledgements. The amino acid analyses of E. Lund, and the mass spectrometric sequence analyses of $E$. Nebelin and of $P$. Roepstorff are gratefully acknowledged. $H$. Andersen is thanked for help in construction of the synthesizer. This work was supported by grants from the Danish Medical Research Council to M. Simonsen, and by grants from King Christian X'th Foundation, Johann \& Hanne Weimann, nee Seedorf's Foundation, P. Carl Petersens Foundation, and the Danish Medical Research Council to P.S.

\section{REFERENCES}

1. Merrifield, R. B. J. Am. Chem. Soc. 85 (1963) 2194.

2. Erickson, B. W. and Merrifield, R. B. In Neurath, H. and Hill, R. L., Eds., The Proteins, 3rd Ed., Academic, New York 1976, Vol. 2, p. 257.

3. Meienhofer, J. In Li, C. H., Ed., Hormonal Proteins and Peptides, Academic, New York 1973 , p. 45.

4. Brunfeldt, K. Acta Phys. Chem. 23 (1977) 499.

5. Villemoes, P., Christensen, T. and Brunfeldt, K. Acta Chem. Scand. B 32 (1978) 703.

6. Sørup, P. J. Chromatog. 160 (1978) 221.

7. Brunfeldt, K., Roepstorff, $P$. and Thomsen, J. Acta Chem. Scand. 23 (1969) 2906.

8. Sørup, P., Junager, F. and Hvidt, A. Biochim. Biophys. Acta 494 (1977) 9.

9. Sørup, P. Hoppe-Seyler's Z. Physiol. Chem. 358 (1977) 97.

10. Sørup, P. and Koch, C. Scand. J. Immunol. 6 (1977) 31 .

11. Sørup, P. Scand. J. Immunol. 8 (1978) 303.

12. Polzhofer, K. P. and Ney, K. H. Tetrahedron 26 (1970) 3221.

13. Feinberg, R. S. and Merrifield, R. B. J. Am. Chem. Soc. 97 (1975) 3485.

Acta Chem. Scand. B 33 (1979) No. 9
14. Sano, S. and Kawanishi, S. Biochem. Biophys. Res. Commun. 51 (1973) 46.

15. Bonora, G. M., Toniolo, C., Fontana, A., DiBello, C. and Scoffone, E. Biopolymers 13 (1974) 157.

16. Sano, S. and Kawanishi, S. J. Am. Chem. Soc. 97 (1975) 3480.

17. Erickson, B. W. and Merrifield, R. B. J. Am. Chem. Soc. 95 (1973) 3750.

18. Engelhard, M. and Merrifield, R. B. J. Am. Chem. Soc. 100 (1978) 3559.

19. Bodanszky, M., Tolle, J. C., Deshmane, S. S. and Bodanszky, A. Int. J. Pept. Protein Res. 12 (1978) 57.

20. Schnabel, E. Justus Liebigs Ann. Chem. 702 (1967) 188.

21. Feinberg, R. S. and Merrifield, R. B. Tetrahedron 30 (1974) 3209.

22. Stewart, J. M. and Young, J. D. Solid Phase Peptide Synthesis, Freeman, San Fransisco 1969.

23. Losse, G., Grenzer, W. and Neubert, $\mathbf{K}$. Z. Chem. 8 (1968) 21.

24. Gisin, B. F. Helv. Chim. Acta 56 (1973) 1476.

25. Brunfeldt, K., Halstrøm, J. and Roepstorff, P. Acta Chem. Scand. 23 (1969) 2830.

26. Brunfeldt, K. and Cristensen, T. FEBS Lett. 19 (1972) 345.

27. Roepstorff, P., Spear, R. K. and Brunfeldt, K. FEBS Lett. 15 (1971) 237.

28. Beyerman, H. C., Lie, T. S. and van Veldhuizen, C. J. In Nesvadba, H., Ed., Peptides 1971, North Holland, Amsterdam 1973 , p.162.

29. Manning, M. J. Am. Chem. Soc. 90 (1968) 1348.

30. Takashima, H., du Vigenaud, V. and Merrifield, R. B. J. Am. Chem. Soc. 90 (1968) 1323.

31. Krumdieck, C. L. and Baugh, C. M. Biochem. 8 (1969) 1568.

32. Hancock, W. S., Prescott, D. J., Nultry, W. L., Weinstraub, J., Vagelos, P. R. and Marshall, G. R. J. Am. Chem. Soc. 93 (1971) 1799.

33. Ben-Ishai, D. and Berger, A. J. Org. Chem. 17 (1952) 1564.

34. Trudelle, Y. and Spach, G. Tetrahedron Lett. (1972) 3475.

35. Schou, O., Salem, E., Lund, E. and Larsen, P. In Siemion, I. Z. and Küpryszewski, G., Eds., Peptides 1978, Wroclaw University Press, Wroclaw 1979, p. 215.

36. Yonezawa, H., Takahashi, N., Ohno, M. and Izumiya, N. Int. J. Pept. Proteln. Res. 11 (1978) 19.

37. Leibfritz, D., Mayr, W., Oekonomopulos, R. and Jung, G. Tetrahedron 34 (1978) 2045.

38. Gisin, B. F. and Merrifield, R. B. J. Am. Chem. Soc. 94 (1972) 3102.

Received April 27, 1979. 